\title{
CristalizaÇÃo: uma APLICAÇÃo em deCoraÇÃo
}

\section{Ana Tavares Sousa*}

\section{INTRODUÇÃO}

A disciplina de Área de Projecto, do actual currículo do $12^{\circ}$ ano de escolaridade, visa a aplicação dos saberes e dos saberes fazer, adquiridos pelos alunos ao longo do Ensino Secundário. Neste âmbito, com um grupo de alunas do curso de Ciências e Tecnologias, da Escola Secundária Stuart Carvalhais, foi desenvolvido o projecto Ciência na Decoração.

Este projecto tinha como objectivo a elaboração de velas de gel, decoradas com cristais de sais simples e duplos, sintetizados ou apenas cristalizados em laboratório.

O uso da cristalização de sais simples e duplos para fins decorativos começou por ser abordado e trabalhado, entre outros, pela professora Clementina Teixeira [1-4]. Por outro lado a síntese de sais duplos faz parte do actual programa do $11^{\circ}$ ano de Física e Química A, como aprendizagem de técnicas laboratoriais, quer na sua componente prática, quer na componente teórica de planificação e preparação do trabalho experimental.

\section{Desenvolvimento do PROJeCto}

Dado que o grupo de alunas em questão pretendia realizar um trabalho na área da decoração, fazendo velas decorativas, foi-lhes sugerido que tentassem a introdução de cristais de sais duplos e simples em velas de gel.

Como as alunas queriam representar os quatro elementos em que os filósofos gregos dividiam a matéria (água, fogo, terra e ar), foi elaborada uma lista das substâncias viáveis de sintetizar e cristalizar no laboratório da Escola e que apresentavam cores e formatos alusivos a esses elementos.

Escola Secundária Stuart Carvalhais
Assim, e condicionados pelos reagentes disponíveis, decidiu-se quais os cristais a sintetizar e a cristalizar. A principal preocupação técnica na escolha dos cristais foi a de que o ponto de fusão destes não fosse superior ao ponto de fusão do gel, uma vez que eles tinham de ser colocados no interior do gel antes do mesmo solidificar.

A tabela 1 resume as sínteses e cristalizações feitas. Os procedimentos apresentados destinam-se à produção de cristais de dimensões adequadas a recipientes com capacidade entre os 100 e os $200 \mathrm{~mL}$. cumpridas todas as normas de segurança, quer respeitantes ao trabalho laboratorial, quer às sínteses efectuadas, de acordo com os reagentes utilizados. Dado que alguns dos reagentes são bastante tóxicos, como o níquel e o crómio, foi colocado nas velas uma etiqueta, alertando para que estas eram meramente decorativas e não deveriam ser postas a arder.

As velas eram ainda acompanhadas de uma brochura onde se explicava um pouco da química dos cristais (a classificação em schönites e alúmens, as formas de cristalização,

Tabela 1 Resumo dos cristais sintetizados

\begin{tabular}{|c|c|c|}
\hline Sais sintetizados ou cristalizados & Reagentes utilizados & $\begin{array}{l}\text { Elemento grego } \\
\text { representado }\end{array}$ \\
\hline $\begin{array}{l}\text { Sulfato de cobre (II) pentahidratado } \\
\qquad \mathrm{CuSO}_{4} \cdot 5 \mathrm{H}_{2} \mathrm{O}\end{array}$ & $\begin{array}{c}\mathrm{CuSO}_{4} \cdot 5 \mathrm{H}_{2} \mathrm{O}-22,5 \mathrm{~g} \\
50 \mathrm{~mL} \mathrm{H} \mathrm{H}_{2} \mathrm{O}\end{array}$ & Água \\
\hline $\begin{array}{l}\text { Sulfato de níquel e potássio hexahidratado } \\
\qquad \mathrm{K}_{2} \mathrm{Ni}\left(\mathrm{SO}_{4}\right)_{2} \cdot 6 \mathrm{H}_{2} \mathrm{O} \text { (schönite) }\end{array}$ & $\begin{array}{c}\mathrm{K}_{2} \mathrm{SO}_{4}-10,0 \mathrm{~g} \\
\mathrm{NiSO}_{4} \cdot 6 \mathrm{H}_{2} \mathrm{O}-15,0 \mathrm{~g} \\
200 \mathrm{~mL} \mathrm{H} \mathrm{H}_{2} \mathrm{O}\end{array}$ & Terra \\
\hline $\begin{array}{l}\text { Sulfato de crómio e potássio } \\
\text { dodecahidratado } \\
\mathrm{KCr}\left(\mathrm{SO}_{4}\right)_{2} \cdot 12 \mathrm{H}_{2} \mathrm{O} \text { (alúmen) }\end{array}$ & $\begin{array}{c}\mathrm{K}_{2} \mathrm{SO}_{4}-5,7 \mathrm{~g} \\
\mathrm{Cr}_{2}\left(\mathrm{SO}_{4}\right)_{3} \cdot 1 \mathrm{OH}_{2} \mathrm{O}-18,7 \mathrm{~g} \\
50 \mathrm{~mL} \mathrm{H}_{2} \mathrm{O}\end{array}$ & Fogo \\
\hline $\begin{array}{c}\text { Hexacianoferrato (II) de potássio } \\
\text { trihidratado } \\
\left.\mathrm{K}_{4}\left[\mathrm{Fe}(\mathrm{CN})_{6}\right)\right] \cdot 3 \mathrm{H}_{2} \mathrm{O}\end{array}$ & $\begin{array}{c}\left.\mathrm{K}_{4}\left[\mathrm{Fe}(\mathrm{CN})_{6}\right)\right] \cdot 3 \mathrm{H}_{2} \mathrm{O}-50,0 \mathrm{~g} \\
100 \mathrm{~mL} \mathrm{H}{ }_{2} \mathrm{O}\end{array}$ & Fogo \\
\hline $\begin{array}{l}\text { Sulfato de amónio e magnésio } \\
\text { hexahidratado } \\
\left(\mathrm{NH}_{4}\right) \mathrm{Mg}\left(\mathrm{SO}_{4}\right)_{2} \bullet 6 \mathrm{H}_{2} \mathrm{O} \text { (schönite) }\end{array}$ & $\begin{array}{c}\mathrm{Mg}\left(\mathrm{SO}_{4}\right)_{2} \cdot 7 \mathrm{H}_{2} \mathrm{O}-13,5 \mathrm{~g} \\
\left(\mathrm{NH}_{4}\right)_{2} \mathrm{SO}_{4}-10,0 \mathrm{~g} \\
150 \mathrm{~mL} \mathrm{H} \mathrm{O}\end{array}$ & $\operatorname{Ar}$ \\
\hline $\begin{array}{l}\text { Sulfato de cobre e cálcio } \\
\text { Composição desconhecida }\end{array}$ & $\begin{array}{c}\text { Mistura existente no laboratório } \\
-22,5 \mathrm{~g} \\
50 \mathrm{~mL} \mathrm{H}_{2} \mathrm{O}\end{array}$ & Água \\
\hline
\end{tabular}

Parte dos recipientes usados foram copos e boiões de iogurte. Aproveitaram também alguns copos de vidro de velas já ardidas. Deste modo reciclaram recipientes de vidro.

Os suportes de cristalização utilizados foram pedras, conchas, arame e fio de algodão. A técnica utilizada nas sínteses foi a descrita por Clementina Teixeira em On the Rocks [2]. Foram etc.) e se descreviam as regras de segurança a aplicar.

À medida que as alunas se familiarizaram com a técnica de síntese dos cristais e de preparação do gel, foram experimentando vários processos de colocação dos cristais no gel, produzindo efeitos diversos.

As figuras 1 a 4 ilustram algumas das velas produzidas. 

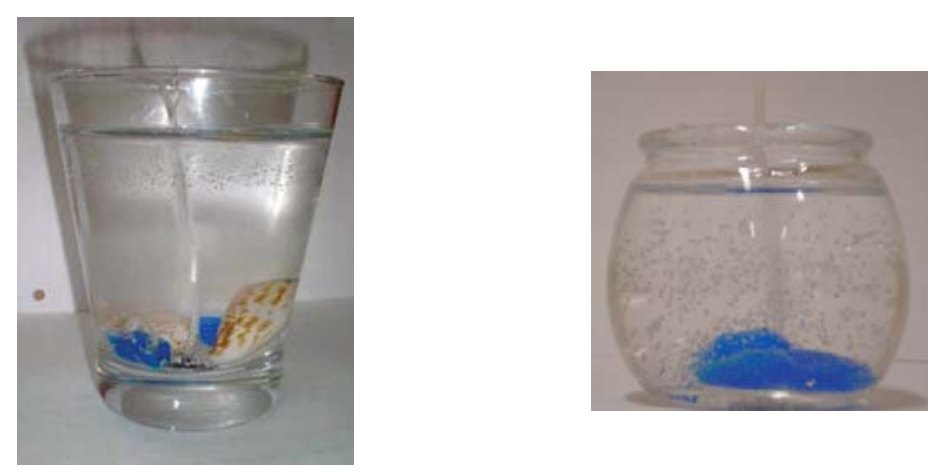

Figura 1 Água
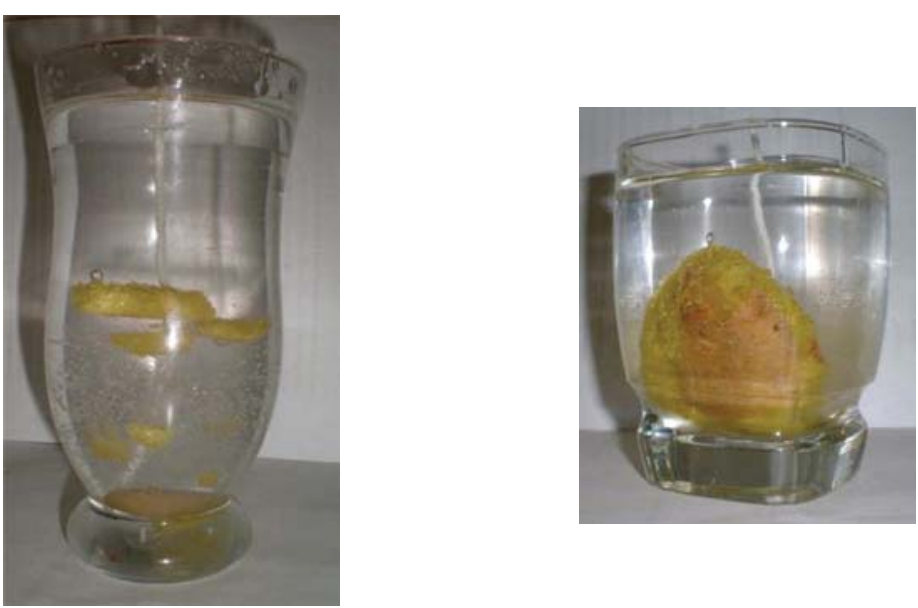

Figura 2 Fogo
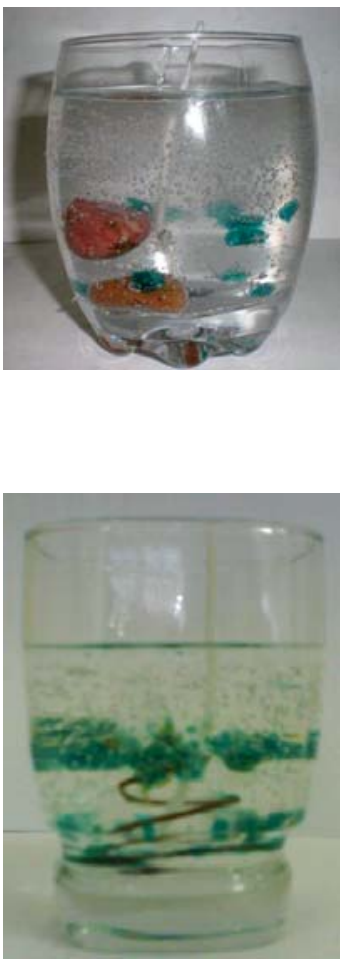
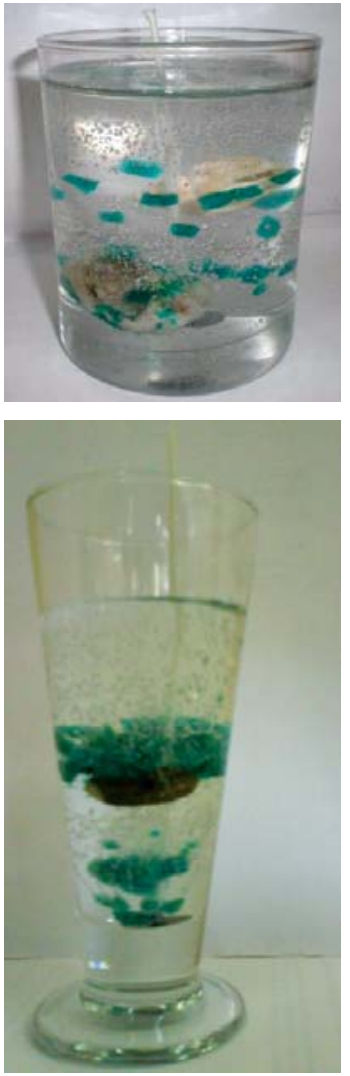

Figura 3 Terra

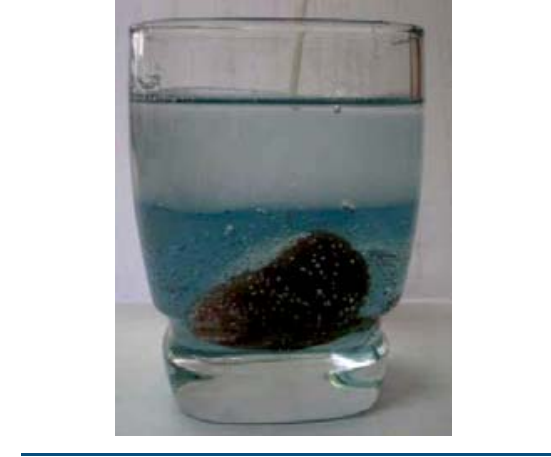

Figura $4 \mathrm{Ar}$

\section{Conclusão}

Este projecto permitiu às alunas desenvolver a prática de trabalho em laboratório, em todas as suas vertentes: planificação, manuseamento de material, aplicação correcta das regras de segurança, resolução de problemas pontuais e imprevistos, tomadas rápidas de decisão, autonomia. Este foi talvez o aspecto mais significativo da concretização deste projecto, uma vez que o actual currículo do Ensino Secundário não permite o desenvolvimento consciente da prática laboratorial. Durante os $10^{\circ}$ e $11^{\circ}$ anos os alunos passam pelos laboratórios e executam mecanicamente os protocolos que the são fornecidos, dependendo quase totalmente do auxílio do professor, não chegando no final a dominar nenhuma técnica. Embora não sejam estes os objectivos preconizados pelos programas, a aplicação dos mesmos em sala de aula acaba por conduzir a tal. A quantidade de temas abordados, quer teóricos, quer práticos, é demasiada para o tempo previsto para a sua leccionação, conduzindo a um amontoado de conceitos sem relação entre si, uma vez que os alunos não têm tempo para consolidar os conhecimentos que lhes são transmitidos.

Este projecto permitiu assim colmatar algumas das falhas existentes na aprendizagem dos alunos de Ciências e Tecnologias, que se vêm a notar desde a extinção das disciplinas de Técnicas Laboratoriais.

Como as próprias alunas referiram no seu relatório final, no início do projecto sentiram que não dominavam conhecimentos básicos de Química, que supostamente estariam consolidados. 
A motivação para avançar levou-as a estudar novamente as matérias, tendo ultrapassado as suas dificuldades. No final sentiam-se já à vontade no laboratório de Química, sendo capazes de interpretar resultados obtidos e solucionar problemas, recorrendo aos conhecimentos teóricos necessários.

As velas feitas tiveram bastante sucesso na comunidade escolar, em particular pelos efeitos que os cristais produzem dentro do gel.

O projecto foi um início simples, dada a falta de experiência das alunas, a partir daqui muitas alternativas podem ser seguidas, tal como as próprias alunas abordaram no seu relatório final. Uma das ideias que surgiu durante a feitura das velas foi a sua construção em patamares. Por um acaso experimental as alunas deixaram secar demasiado uma porção de gel já introduzido no recipiente antes de colocarem cristais. Colocaram por cima mais gel e cristais e verificaram que o efeito era bastante interessante. Terminado o projecto existiam já inúmeras ideias inovadoras.

Pretende-se aqui comunicar uma aplicação prática dos conhecimentos adquiridos na disciplina de Física e Química A. Este artigo não deve ser encarado como um protocolo para elaboração de velas a distribuir no mercado.

A concretização deste projecto na perspectiva de feitura de velas para arderem é viável. Mas para tal os critérios de escolha dos cristais a utilizar terão de ser diferentes. A partir desta ideia inicial poderão ser concebidos muitos outros projectos, tantos quantos a imaginação nos permitir.

As alunas do $12^{\circ} \mathrm{D}(2008 / 2009)$ Escola Secundária Stuart Carvalhais:

Ana Figueiredo, Ana Soraia Guanilho, Joana Correia, Mafalda Ferreira, Sadeline Faria

\section{REFERÊNCIAS}

[1] C. Teixeira, A. Santana, C. Mesquita, Boletim da Sociedade Portuguesa de Química 53 (1994) 50.

[2] C. Teixeira, O Livro das Pedras: Manual dos Sistemas Modulares para Cristalização "On the Rocks", ed. do autor (Novembro de 1995).

[3] C. Teixeira, Manual de Experiências das Acções de Formação da FOCO - "As Rochas Ornamentais no Ensino da Química", Instituto Superior Técnico (1996).

[4] C. Teixeira, A. Tavares Sousa, I. Trigueiros, "Cristalização: Síntese de Sais Duplos", Boletim da Sociedade Portuguesa de Química 66 (1997) 25.

\section{Actualidade Científica}

\section{Sequestração de Carbono: dificul- DADES EM A IMPLEMENTAR}

Foi referido no número anterior do Química, a respeito do aquecimento global e da sua relação com o aumento da concentração de $\mathrm{CO}_{2}$ na atmosfera, que uma das soluções propostas para combater este efeito passa pela captura e sequestração de $\mathrm{CO}_{2}$ em depósitos subterrâneos.

Apesar de esta medida ser apresentada como uma solução de curto/ médio prazo, ela parece não estar a vingar, apesar de a indústria do petróleo estar já desde há quarenta anos a injectar $\mathrm{CO}_{2}$ no subsolo para facilitar a extracção do petróleo.

Segundo a Agência Internacional de Energia, a forma mais barata de reduzir a metade as emissões de dióxido de carbono em 2050 seria usar a captura e sequestração de carbono para contribuir com $20 \%$ dos cortes neces- sários. Em 2008, o G8 declarou que 20 grandes instalações deveriam ser iniciadas até finais de 2010. Contudo, verifica-se um atraso significativo: há apenas sete grandes projectos e a maioria destes usam o gás para libertar o petróleo aprisionado, um processo que não foi projectado para armazenar o dióxido de carbono. Há muita investigação e discussão sobre este tema mas o progresso real é muito fraco. Para os investidores, este parece ser ainda um negócio pouco atractivo porque é muito dispendioso (em particular a captura do $\mathrm{CO}_{2}$ ) e a sua implementação em larga escala acabará por tornar a energia mais cara. Contudo, este não é o único obstáculo à sua implementação.

A revista Nature divulga, no seu número do passado dia 10 de Fevereiro, que a ideia de armazenamento do $\mathrm{CO}_{2}$ no subsolo parece não convencer as populações. Traz um exemplo de uma proposta da Shell de injectar
400.000 toneladas de $\mathrm{CO}_{2}$ sob um centro comercial antigo em Barendrecht, na Holanda, e que, embora contando com o apoio explícito do governo holandês, encontrou forte oposição dos residentes. Estes, não estando convencidos de que o processo é seguro e ambientalmente benéfico, opõem-se à sua implementação numa zona residencial. O conflito de interesses acentuou-se, tendo o presidente da câmara de Barendrecht ameaçado processar a Shell, em resposta a uma decisão do parlamento holandês de prosseguir com o projecto.

Apesar de o aquecimento global (e das suas previstas consequências) ser hoje um tema muito divulgado e conhecido da opinião pública, esta parece não estar ainda preparada para a implementação de algumas das medidas propostas para o combater. 


\section{Actualidades Científicas}

\section{GrafenO: DESENVOLVIMENTOS RECENTES}

Descoberto em 2004, o grafeno - foIhas de grafite com apenas um átomo de espessura - tem sido descrito como um condutor eléctrico muito bom, um semicondutor, usado no fabrico de transístores, e um material muito forte. De facto, segundo um estudo publicado na revista Science em 2008 (321, pp385-388), por um grupo da Universidade Americana de Columbia, o grafeno é mesmo o material mais resistente de sempre. Mas são as suas propriedades eléctricas e ópticas as que recentemente mais atenção têm atraído.

Foram recentemente apresentados na Nature Nanotechnology (DOI: 10.1038/nnano.2009.474) avanços importantes para a aplicação do grafeno na electrónica. Uma equipa, formada por investigadores ingleses, suecos e italianos conseguiu obter grafeno com dimensões suficientes para ser usado em electrónica e foi capaz de medir as suas propriedades eléctricas com precisão sem precedentes.
Até então, era possível obter grafeno em pequenas folhas com fracções de milímetro. A exfoliação e a sua remoção com fita-cola a partir de grafite eram duas técnicas comuns. Neste estudo, a equipa foi capaz de produzir grafeno sobre carboneto de silício de forma prática e facilmente escalável.

JM

\section{UM NOVO CATALISADOR PARA A OXIDA- ÇÃO DA ÁGUA}

A energia solar apresenta-se hoje como uma das mais importantes fontes de energia renovável, embora seja ainda limitada a nossa capacidade de a usar.

O desenvolvimento de células fotovoltaicas tem sido objecto de um crescente interesse, com desenvolvimentos tecnológicos que envolvem vários materiais e arquitecturas de dispositivos. Contudo, estas funcionam apenas enquanto houver luz solar, pelo que é necessário investir em sistemas de armazenamento da energia eléctrica gerada.

A outra alternativa para a utilização da energia solar é a produção de combustível solar, passível de ser armazenado e usado quando não houver luz solar.

Para efectuar esta captura da energia solar sob a forma química é necessário desenvolver tecnologias adequadas. Em particular, procura-se optimizar a fotossíntese artificial, que combina uma espécie fotoactiva ou sensibilizador, que promove a separação de carga a partir de um estado excitado. O electrão libertado é usado na redução de protões ou do dióxido de carbono.

O buraco produzido é compensado com a captura de um electrão proveniente da oxidação da água. Uma das limitações actuais ao desenvolvimento de combustíveis solares é a reacção de oxidação da água, ou mais concretamente o desenvolvimento de um catalisador desta reacção. A água é a única fonte de electrões capazes de reduzir os protões a $\mathrm{H}_{2}$ ou reduzir $\mathrm{CO}_{2}$ a combustíveis carbonáceos a uma escala global.

O desenvolvimento de um catalisador capaz de promover a oxidação da água, $2 \mathrm{H}_{2} \mathrm{O} \rightarrow \mathrm{O}_{2}+4 \mathrm{H}^{+}+4 \mathrm{e}$, e que possa ser usado em grande escala, é uma tarefa difícil de concretizar. Esse catalisador tem que permanecer activo durante longos períodos de tempo ou ser facilmente regenerado e ser preparado a partir de materiais baratos e disponíveis. Os catalisadores actualmente disponíveis tendem a perder rapidamente a sua actividade catalítica e não são sujeitáveis a processos de auto-regeneração.

Uma equipa de investigadores americanos e franceses reportou um catalisador para a oxidação da água, solúvel em água, que possui quatro átomos de cobalto no seu centro reactivo (Science 328(2010) 342-345). Este encontra-se rodeado de ligandos que são aniões polioxotungstato.

Este catalisador parece combinar as propriedades de catalisadores já conhecidos e eliminar algumas das suas limitações, prometendo contribuir para um significativo avanço desta área.

(Adaptado de J. K. Hurst em Perspectives, Science $\mathbf{3 2 8}$ (2010) 315) JM 